\title{
Hypercalcaemia due to the coexistence of parathyroid adenoma and myelomatosis
}

\author{
RM FRANCIS, ${ }^{*}$ AG BYNOE, $\dagger$ C GRAY $\ddagger$
}

From the *MRC Mineral Metabolism Unit, the †Department of Haematology, The General Infurmary at Leeds, Great George Street, Leeds LS1 3EX and the $\ddagger$ Department of Pathology, University of Leeds, Leeds LS2 $9 J T$

SUMMARY A 70-year-old woman presented with back pain due to vertebral crush fractures and was found to have hypercalcaemia. Investigation revealed evidence of both primary hyperparathyroidism and Bence Jones myeloma and this was subsequently confirmed at necropsy. This is the first description of a case in which the simultaneous occurrence of both diseases was reliably established. The case illustrates the difficulty in identifying the cause of hypercalcaemia in some patients, and emphasises the need to consider the diagnosis of myeloma in all cases of hypercalcaemia.

In a recent series ${ }^{1}$ of 153 patients with hypercalcaemia, the two commonest causes were malignant disease (89 cases) and primary hyperparathyroidism (51 cases). The biochemical abnormalities in hyperparathyroidism include ${ }^{2}$ hypercalcaemia, raised plasma parathyroid hormone (PTH), decreased tubular reabsorption of phosphate (TmP), hypophosphataemia, increased tubular reabsorption of calcium ( $\mathrm{TmCa}$ ), increased calcium absorption, raised plasma 1,25 dihydroxyvitamin $\mathrm{D}$, increased urinary hydroxyproline and increased plasma alkaline phosphatase. Owing to the spectrum of disease, not all these abnormalities are present in every patient with hyperparathyroidism, and as a result hypercalcaemia may pose a diagnostic problem to the clinician. We report a case in which there was strong evidence of both primary hyperparathyroidism and myeloma.

\section{Case report}

A 70-year-old woman presented with a six-month history of back pain, loss of height and increasing kyphosis. She had been seen elsewhere and found on $x$-ray examination to have vertebral crush fractures, which had been treated with calcium supplements and low dose vitamin D (1000 units daily). The only abnormalities on physical examination were a dorsal kyphosis and tenderness over the dorsal and lumbar spine.
Investigation revealed hypercalcaemia (plasma calcium $2.90 \mathrm{mmol} / \mathrm{l}$, normal $2.25-2.60 \mathrm{mmol} / \mathrm{l}$ with a normal plasma phosphate $(0 \cdot 83 \mathrm{mmol} / \mathrm{l})$, creatinine $(83 \mu \mathrm{mol} / \mathrm{l})$ and alkaline phosphatase $(8.4 \mathrm{KA}$ units). There was evidence of increased bone resorption with a high fasting urine hydroxyproline: creatinine ratio (OHPr:Cr) $(0.025$ molar units, normal $<0.020$ ). The calculated TmCa was normal $(2.03 \mathrm{mmol} / \mathrm{g}$ glomerular filtrate, normal $\bumpeq 2 \cdot 0)$, 专 whilst the TmP was reduced $(0.67 \mathrm{mmol} / 1$ glomerular filtrate, normal $\bumpeq 1 \cdot 0$ ). Radiocalcium absorption was low $(0.15$ fraction of dose/hour, normal 0.30 1.40 ) despite a marginally raised plasma 25 hydroxy vitamin D concentration $(221.5 \mathrm{nmol} / 1$, normal 42.5-215.0 nmol/l) due to the previous vitamin $D$ therapy. The plasma PTH concentration was raised at $560 \mathrm{pg} / \mathrm{ml}$ (normal $125-375 \mathrm{pg} / \mathrm{ml})$. The haemo- $\rightarrow$ globin and ESR were both normal. Chest $x$-ray was? normal; but $x$-rays of the spine showed multiple $N$ crush fractures, and $x$-rays of the hands, skull and pelvis showed osteopenia but none of the radiologi- 0 cal features of hyperparathyroidism. There were now lytic lesions and no metastatic deposits.

It was concluded that the hypercalcaemia was dues to increased bone resorption, and the raised plasma PTH and low TmP suggested a diagnosis of primary? hyperparathyroidism. As the patient was reluctant ${ }^{\circ}$ to consider parathyroidectomy, she was started on $\frac{\vec{\Phi}}{\mathrm{D}}$ norethisterone $5 \mathrm{mg}$ daily in an attempt to reduce $\stackrel{?}{?}$ bone resorption. There was improvement in the $\underset{\mathbb{Q}}{\mathbb{Q}}$ back pain and biochemical evidence of decreasedo resorption ( $\mathrm{OHPr}: \mathrm{Cr}$ 0.014). 


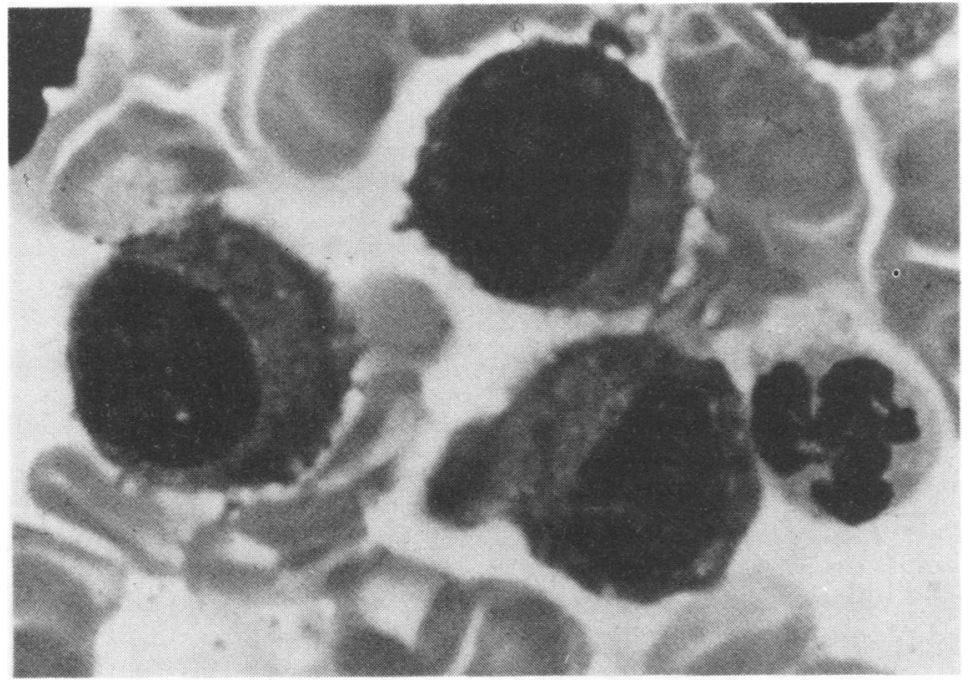

Fig. 1 Marrow smear showing increased numbers of plasma cells. May-Grünwald-Giemsa $\times 1900$.
Over the following two months, the back pain worsened and was associated with pain in the ribs and sternum. The hypercalcaemia became more marked (plasma calcium $3.28 \mathrm{mmol} /$ ) due to increased bone resorption (OHPr:Cr 0.039) and a deterioration in renal function (plasma creatinine $133 \mu \mathrm{mol} / \mathrm{l})$. She developed a normochromic normocytic anaemia (Hb 10.2 g/dl, MCV $91.0 \mathrm{fl}, \mathrm{MCH}$ $30.4 \mathrm{pg}$ ) and the ESR rose to $40 \mathrm{~mm} / \mathrm{h}$.

Sternal bone marrow aspiration showed a hypercellular marrow with plasma cells comprising more than $70 \%$ of nucleated cells (Fig. 1). Many of these plasma cells were morphologically abnormal. Immunofluorescent staining showed that more than $75 \%$ of the plasma cells contained cytoplasmic lambda light chain but no heavy chain. Electrophoresis of serum showed a band in the fast gamma region, with a corresponding band in the urine. Immunoelectrophoresis confirmed that these bands were monoclonal lambda light chain.

An iliac crest bone biopsy showed almost total absence of trabecular bone, extensive resorption cavities in the cortical bone, and abnormal plasma cells in the marrow.

The patient therefore fulfilled two of the three Medical Research Council criteria ${ }^{3}$ for a diagnosis of myeloma, and specifically of lambda Bence Jones myeloma. She was transferred to the Haematology Unit, and treated with $1 \mathrm{mg}$ intravenous vincristine, and a seven day course of melphalan $10 \mathrm{mg}$ od and prednisolone $40 \mathrm{mg}$ od. She was rehydrated, transfused two units of packed cells and maintained on at least three litres of oral fluids daily. The hypercalcaemia and renal function improved (plasma calcium $2.97 \mathrm{mmol} / \mathrm{\text {; }}$; creatinine $115 \mu \mathrm{mol} / \mathrm{l}$ ) but 10 days after transfer she developed increased bone pain and urinary retention without neurological signs of spinal cord compression. Examination of the urine showed a coliform urinary tract infection for which she was treated with ampicillin. Fluid input was maintained with intravenous saline, and urine output continued at more than $1.5 \mathrm{l} / \mathrm{day}$. However there was continued clinical and biochemical deterioration (plasma calcium $3.03 \mathrm{mmol} / \mathrm{f}$; creatinine $182 \mu \mathrm{mol} / \mathrm{l}$ ) and she died three weeks after the diagnosis of myeloma had been made.

\section{NECROPSY}

Bone marrow at four sites-sternum, rib, iliac crest and lumbar vertebra - was replaced by soft, brown crumbly tissue. The spleen was of normal weight $(150 \mathrm{~g})$ and appeared normal externally. Histologically, the bone marrow at all four sites showed increased cellularity, with increased numbers of plasma cells, including binucleate and other abnormal forms. The spleen showed aggregations of plasma cells in the red pulp. The right lower parathyroid gland was enlarged $(300 \mathrm{mg})$ and two other parathyroid glands were found. Histologically, the enlarged parathyroid gland contained a single adenoma (Fig. 2), which showed compression of residual normal acini around its margin, but neither fibrous septa nor a capsule were present. The other two parathyroid glands were normal (Fig. 3).

There was a friable, adherent thrombus partially occluding the left renal vein one centimetre from its junction with the inferior vena cava. Histologically, the thrombus showed early organisation at its margin.

The kidneys appeared normal externally, but on 


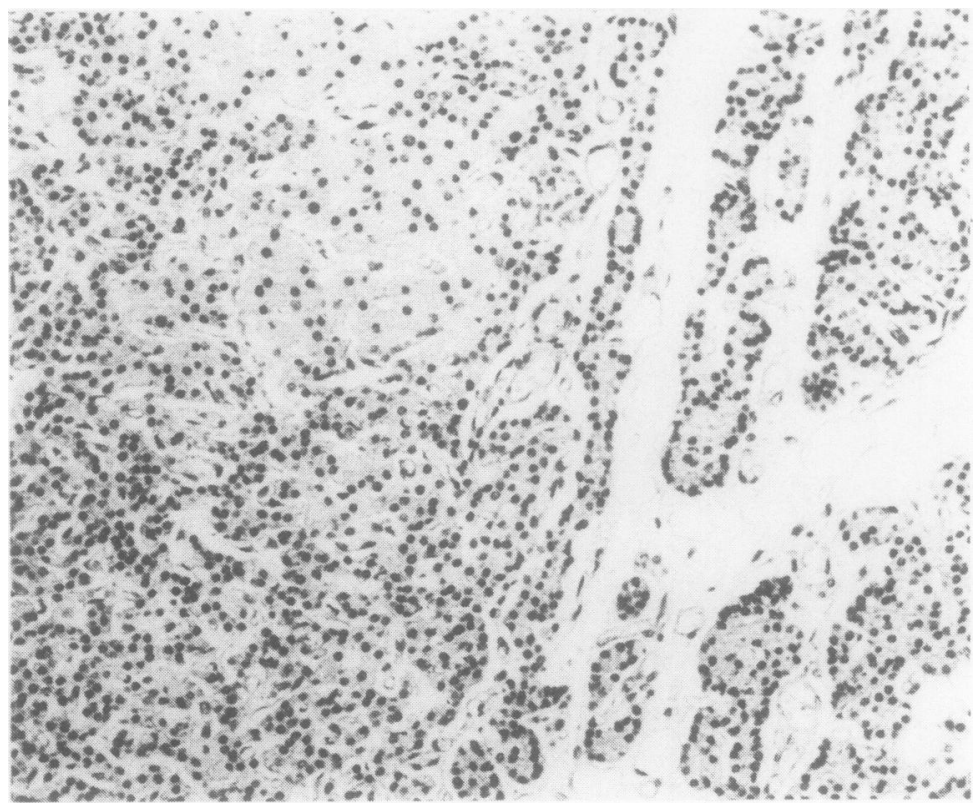

Fig. 2 Section of right lower parathyroid gland showing a portion of the adenoma (left), which compresses residual normal acini (right). Haematoxylin and eosin $\times 290$.

histology they showed numerous proteinaceous casts in tubules, associated with a foreign-body giant cell reaction (Fig. 4). There was no evidence of con-
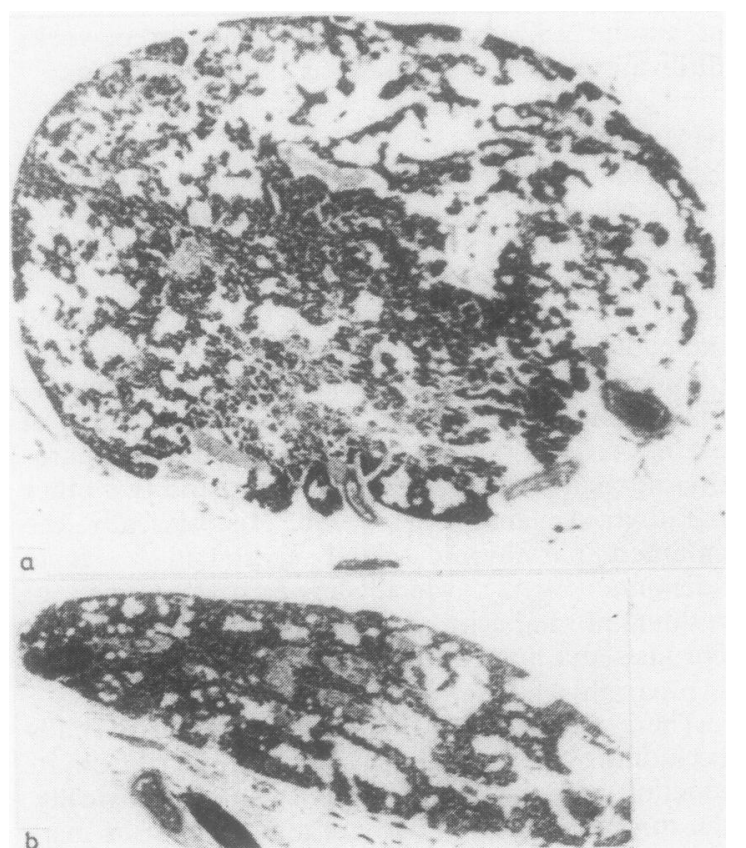

Fig. $3(\mathrm{a}, \mathrm{b})$ Sections of the two other normal parathyroid glands. Haematoxylin and eosin $\times 30$. gestion, infarction, inflammation or amyloid in either kidney. Metastatic calcification was not evident on contact radiography of the kidney.

The skull was normal, but all ribs showed marked softening, and there were pathological fractures of six ribs anteriorly. The sternum and vertebral bodies also showed marked softening. Histologically, cancellous bone showed loss and reduction in size of bony trabeculae with increased numbers of osteoblasts and prominent osteoclastic activity. In addition to widespread infiltration by plasma cells, the marrow spaces showed areas of loose fibrous connective tissue containing thin-walled capillary blood vessels. These appearances were consistent with osteitis fibrosa cystica with concurrent infiltration by myeloma.

Plasma cells in the spleen and bone marrow, and the renal tubular casts, showed intense monoclonal staining for lambda light chain by a peroxidaseantiperoxidase method; no immunoglobulin heavy chain was detected. No other significant abnormality was found in the other organs.

\section{Discussion}

Hyperparathyroidism produces hypercalcaemia by increasing calcium absorption, bone resorption and tubular reabsorption of calcium, and in severe cases by the development of renal failure. ${ }^{4}$ Not all these mechanisms operate in every case of primary hyperparathyroidism; only the minority have bone dis- 


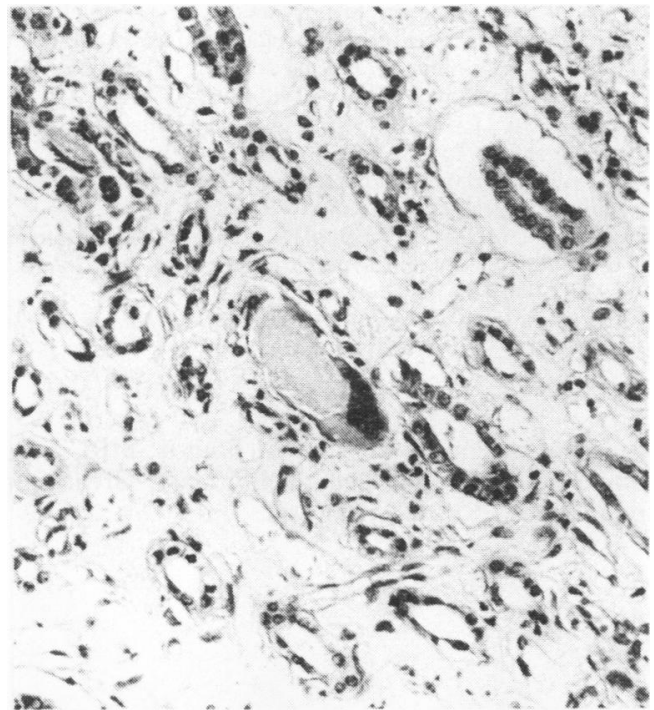

Fig. 4 Section of renal medulla showing tubular casts with a foreign-body giant cell reaction- "myeloma kidney." Haematoxylin and eosin $\times 290$.

ease $^{2}$ and some of these patients have malabsorption of calcium. ${ }^{5}$ Malignant disease may produce hypercalcaemia by the direct effect of skeletal metastases, by ectopic PTH production or by the secretion of other bone resorbing substances such as prostaglandins. ${ }^{\circ}$ Myeloma causes hypercalcaemia by both increasing bone resorption (possibly mediated by an osteoclast activating factor ${ }^{6}$ ) and by reducing glomerular filtration rate. ${ }^{7}$ In cases of hypercalcaemia not due to hyperparathyroidism, there is usually suppression of PTH production. ${ }^{1}$ The investigation of hypercalcaemia may therefore include measurement of plasma PTH and other indices of PTH activity such as the TmP. This can occasionally be misleading in that the plasma PTH may be high in malignant disease if ectopic PTH production or renal failure is present, and the TmP may be low due to factors other than PTH. ${ }^{8}$ Furthermore a high plasma PTH may not be detected by some assays.

Bence Jones myeloma is notoriously difficult to diagnose because the ESR is often normal, rouleaux may not be seen in the blood film, and a paraprotein band is not always detected in the serum. In cases presenting with hypercalcaemia, the diagnosis may be missed and the hypercalcaemia attributed to another cause.

The incidence of primary hyperparathyroidism is 1 in 2380/yr, ${ }^{9}$ whilst that of myeloma is 1 in $5000 / \mathrm{yr}^{10}$ in Caucasians, of which 20 to $25 \%$ are of Bence
Jones type. The two conditions would therefore be expected to coexist by chance on rare occasions. Two previous reports of the coexistence of primary hyperparathyroidism and myeloma have been published, but both fail to give convincing evidence for one of their diagnoses. Drezner and Lebovitz ${ }^{11}$ described a case of myeloma, which was one of six patients shown to have either parathyroid hyperplasia or adenoma at surgery, but the evidence for myeloma was not presented. Drezner subsequently confirmed (MK Drezner, personal communication, 1981) that the case had a parathyroid adenoma. Jackson and Orland ${ }^{12}$ described a single case of myeloma, and demonstrated a raised plasma PTH after a "parathyroid squeeze" test, which they interpreted as evidence of unilateral parathyroid adenoma. Dexter et $\mathbf{l}^{13}$ reported three cases of surgically proven primary hyperparathyroidism with monoclonal gammopathy, but no evidence of myeloma was found during follow-up. Waldenström ${ }^{14}$ mentions further cases of the association, but does not give full references.

In our case, there was biochemical evidence of hyperparathyroidism: hypercalcaemia, raised plasma PTH, decreased TmP and increased urine OHPr:Cr. There was also unequivocal evidence of Bence Jones myeloma: increased abnormal plasma cells in the marrow, containing monoclonal light chain, and a corresponding paraprotein band in the serum and urine. Necropsy confirmed the presence of a parathyroid adenoma and myeloma. The normal size and histology of the other two parathyroid glands excludes the possibility of secondary hyperparathyroidism due to incipient renal failure. The case demonstrates the necessity of considering the diagnosis of myeloma in all cases of hypercalcaemia.

We are indebted to Professor BEC Nordin and Dr JA Child for permission to report the case, Dr M Peacock for the PTH assay, Professor CC Bird for valuable advice, $\mathrm{Mr}$ CS Scott for immunofluorescent studies on the marrow, $\mathrm{Mr} \mathrm{S}$ Toms, and the Department of Medical Photography, Leeds General Infirmary for photographic assistance and Miss KF Gray for assistance with the literature search.

\section{References}

' Fisken RA, Heath DA, Somers S, Bold AM. Hypercalcaemia in hospital patients: clinical and diagnostic aspects. Lancet $1981 ; \mathrm{i}: 202-7$.

${ }_{2}^{2}$ Peacock M. The endocrine control of calcium and phosphorus metabolism and its diseases. Medicine 1978;9:407-17.

${ }^{3}$ Galton DAG, Peto R. A progress report on the Medical Research Council's therapeutic trial in myelomatosis. $\mathrm{Br} J$ Haematol 1968;15:319-20. 
'Kanis JA, Cundy T, Heynen G, Russell RGG. The pathophysiology of hypercalcaemia. Metab Bone Dis Rel Res 1980;2:151-9.

${ }^{s}$ Peacock M. Renal stone disease and bone disease in primary hyperparathyroidism and their relationship to the action of parathyroid hormone on calcium absorption. In: Talmage RV, Owen M, Parsons JA, eds. Calcium regulating hormones. Amsterdam: Excerpta Medica, 1975:78-81.

- Mundy GR, Eilon G, Orr W, Spiro TP, Yoneda T. Osteoclast activating factor: its role in myeloma and other types of hypercalcaemia of malignancy. Metab Bone Dis Rel Res 1980;2:173-6.

${ }^{7}$ Heyburn PJ, Child JA, Peacock M. Relative importance of renal failure and increased bunic iesorption in the hypercalcaemia of myelomatosis. J Clin Pathol 1981;34:54-7.

- Stewart AF, Horst R, Deftos LJ, Cadman EC, Lang R, Broadus AE. Biochemical evaluation of patients with cancer-associated hypercalcaemia: evidence of humoral and nonhumoral groups. $N$ Engl J Med 1980;303:1377-83.
${ }^{9}$ Heath H III, Hodgson SF, Kennedy MA. Primary hyperparathyroidism: incidence, morbidity and potential economic impact in a community. $N$ Engl J Med 1980;302:189-93.

${ }^{10}$ Hobbs JR. Myeloma. Medicine 1980;29:1507-12.

"Drezner MK, Lebovitz HE. Primary hyperparathyroidism in paraneoplastic hypercalcaemia. Lancet 1978;i:1004-6.

12 Jackson RM, Orland MJ. Parathyroid adenoma in a patient with multiple myeloma. South Med J 1979;72:1336-7.

${ }^{13}$ Dexter RN, Mullinax F, Estep HL, Williams RC. Monoclonal IgG gammopathy and hyperparathyroidism. Ann Intern Med 1972;77:759-64.

14 Waldenström J. Diagnosis and treatment of multiple myeloma. New York: Grune and Stratton, 1970.

Requests for reprints to: Dr RM Francis, MRC Mineral Metabolism Unit, The General Infirmary, Great George Street, Leeds LS1 3EX, England. 